\title{
LA DIFUSION DEL LIBERALISMO EN EL PAIS VASCO: DE LA CARTA PASTORAL DE LUIS DE BORBON (1820) A EL LIBERALISMO ES PECADO (1887)
}

\author{
César Gallastegui Aranzabal \\ Profesor encargado. Facultad de Derecho, Universidad de Deusto
}

Sumario: 1. El País Vasco a inicios del siglo XIX. 2. El Trienio Liberal. 2.1. La instalación del liberalismo en el poder: la Carta Pastoral de Luis de Borbón, de 15 de marzo de 1820. 2.2. Los sermones en defensa de la Constitución. 2.3. La extensión de la cultura política: los catecismos políticos. 2.4. La defensa del régimen liberal: la Milicia Nacional. 3. Primera Guerra Carlista: prensa y propaganda. 3.1. Las iniciativas liberales. 4. La construcción del Estado Liberal y la respuesta de las instituciones forales. Contrapropuesta carlista. 5. La literatura antiliberal de fin de siglo.

Sirvan estas líneas como homenaje al Profesor Lucas Verdú, vinculado durante años a la Universidad de Deusto y al País Vasco en una relación que tantos y tan buenos frutos ha dado.

En este artículo pretendemos hacer un breve repaso a algunos de los acontecimientos políticos fundamentales del siglo XIX español y su reflejo en el País Vasco, más concretamente en la producción escrita en euskera. Como es sabido, si dejamos a un lado los textos religiosos, la producción en lengua vasca es exigua. Sin embargo, alrededor de los acontecimientos decimonónicos podemos encontrar aquí y allá algunos elementos de interés en el campo de estudio elegido.

\section{El País Vasco a inicios del siglo XIX}

¿Cuál era la consideración que merecía la lengua vasca a inicios del XIX? A nivel ideológico se puede hablar de una politización de la cuestión lingüística desde finales del siglo precedente: la lengua, ligada al sistema foral, sufría el ataque de ciertos autores que intentaban desprestigiar el euskera para erosionar así el propio estatus político de las provincias vascas en el seno de la monarquía española.

El euskera, tachado de «jerga» o «guirigay», venía a ser prácticamente una invención, «Así en el siglo XII debió comenzar a tener forma y consistencia la lengua empezada a introducir a mediados del siglo VIII 
para figurar sus naturales total independencia», escribía Traggia ${ }^{1}$ en el Diccionario geográfico-histórico de España impulsado por la Real Academia de la Historia.

Este tipo de afirmaciones sobre la antigüedad y originalidad del euskera provocaron una reacción en el País Vasco de la mano de autores como Juan Antonio Mogel, Pablo Pedro Astarloa o Juan Bautista de Erro, quienes escribieron en defensa de la lengua, (publicando obras repletas de elucubraciones lingüísticas e históricas) y provocaron una corriente favorable hacia la lengua vasca. Igualmente, en esos momentos, Guillermo von Humboldt se interesó por el euskera, conoció a Astarloa y divulgó por Europa el interés por la lengua de los vascos, como lo haría medio siglo después el príncipe Bonaparte.

Sin embargo, ¿cuál era la situación real del euskera? Ciertamente no era un idioma cultivado. Escribía el ya citado Juan Antonio Moguel en 1802: «no hay en general gente más desidiosa en cultivar y perfeccionar su idioma, y así es que somos nosotros sus mayores antagonistas, exceptuados algunos pocos sujetos. Nuestra sociedad vascongada ha dormido en este ramo, y así no ha tenido el vascuence una academia ni buenos escritores que le hayan dado cultura particular. Habita como desconocido en los bosques y casas solitarias, y es más que cierto que nuestros rústicos montesinos le saben y hablan maravillosamente y sin las alteraciones que se notan en la gente que debía ser su depósito»² ${ }^{2}$

Pese a ello el euskera era mayoritariamente hablado en los pueblos y en el campo, y sus capitales bilingües (nos referimos a Bizkaia y Gipuzkoa, escenarios principales del presente trabajo). Las clases altas y más cultas se inclinaban por el castellano, la lengua de los negocios y el poder. Esta es la radiografía de la situación en Irún y Lezo escrita en 1807 por el escribano real y secretario de dichos ayuntamientos, Domingo María de Errazu a requerimiento del Tribunal de Justicia de Pamplona: «el ydioma que común y ordinariamente se usa en ambos pueblos es el natibo y bulgar bascongado, que todo originario de la M.N. y M.L. Provincia de Guipuzcoa y Montañas de este Reino lo hereda y adquiere de sus Padres, por ser la primera y unica lengua que generalmente se usa y aprende desde la infancia, y aunque por lo ordinario el trato de Padres e hijos, y aun la informazion en las escuelas publicas de los primeros rudimentos suele ser

${ }^{1}$ Diccionario geográfico histórico de España por la Real Academia de la Historia. Sección I. Comprehende el Reyno de Navarra, Señorío de Vizcaya y Provincias de Alava y Guipúzcoa, II, Imprenta de la viuda de D. Joaquín Ibarra, Madrid, 1802, p. 165.

2 Carta al Señor Don José de Vargas, 26 de febrero de 1802, reproducido en Cartas y disertaciones de Don Juan Antonio Moguel sobre la lengua vascongada. Separata del Memorial histórico español. Tomo VII. Madrid, 1854, p. 704. 
en lengua natiba, y no la castellana, hai muchos padres de familias que a sus hijos los instruien y imponen en ambos hidiomas, pero no debe servir esto de regla porque el número de gentes de esta clase es mui corto respecto al cúmulo de las demás de todo el Pais bascongado» ${ }^{3}$.

Esta situación suponía que la mayoría de la población del País Vasco necesitaba de intermediadores lingüísticos (escribanos y secretarios, receptores y traductores judiciales ${ }^{4}$, párrocos ${ }^{5}$ ) para relacionarse

3 Archivo General de Navarra, Procesos Pendientes, n. ${ }^{\circ}$ 34.886, f. 10; citado en JIMENO Jurio, José María, Navarra. Historia del euskera, Txalaparta, Tafalla, 1997, pp. 182-183. Donostia se mantuvo bilingüe durante todo el siglo; en Bilbao la importancia del euskera disminuyó más rápidamente: en 1797 Fisher escribía en su descripción de la capital «las personas distinguidas todavía no lo han olvidado» («Descripción de Bilbao en el verano de 1797», Estudios vizcaínos, n. 7 y 8, Bilbao, 1973, p. 248) y José Angel de Recacoechea y Uría dejaba en 1794 la siguiente manda: «Es mi voluntad se impongan trece mil quatrocientos reales á Censo y sobre fincas seguras para invertir en Réditos en la Fundación de doce Pláticas Doctrinales que en Bascuence se deverán explicar en la Iglesia Parroquial y Matriz del Señor Santiago de esta Villa, los días Jueves primero de cada mes, desde las tres hasta las quatro en Invierno y de quatro á cinco en Verano, pagando al Predicador que explicase las doce Pláticas Doctrinales trescientos y sesenta reales de vellón, con diez y seis reales anuales para el coste de las velas que se pondrán durante la Plática» (Archivo Histórico Provincial de Vizcaya, Legajo 3501, folio 152; citado en FeIJóo CABALlERo, Pilar, Bizkaia y Bilbao en tiempos de la revolución francesa, Diputación Foral de Bizkaia, Bilbao, 1991, p. 142); en cambio, en 1854 el regidor José M. ${ }^{a}$ Gortazar pide medidas al ayuntamiento en torno al euskera pues siendo las tres cuartas partes del servicio euskaldunes, en toda la Cuaresma no se ha predicado un solo sermón en euskera (Archivo Municipal de Bilbao, Actas Municipales, 1852-54, citado en AgirReAZKuEnaga, Joseba (dir.), Bilbao desde sus alcaldes. Diccionario biográfico de los alcaldes de Bilbao y gestión municipal, en tiempos de revolución liberal e industrial, Vol. 1: 1836-1901, Ayuntamiento de Bilbao, Bilbao, 2002.

${ }^{4}$ La Real Provision de S.M. y Señores el Consejo. De 13 de Octubre de 1815, por la que se aprueban los Aranceles formados para los juzgados del M.N. y M.L. Señorío de Vizcaya, con lo demás que se contiene, Por Eusebio de Larumbe, Bilbao, 1816 (Archivo Foral de Bizkaia, Sección Administrativa, J-1606/313); en su capítulo quinto (De los derechos de los Intérpretes) regula los aranceles de los intérpretes que intervengan en una causa judicial y hace referencia a los traductores de castellano a euskera: «Al Interprete de Bascuence en el caso de que el Juez contemple necesario valerse de él, se señalan dos reales vellon por cada testigo». Recuérdese la ley II del título IX del Fuero de Bizkaia, de 1526: «Con que en eleccion suya sea, si mas quisiere traer los Testigos personalmente ante el Juez, é no llevar el tal acompañado: Cá en tal caso, el Juez sea tenudo de ser presente á la examinacion de los tales Testigos: é si fueren los Testigos Vascongados que no supieren la Lengua Castellana, los examine, y tome con otro Recetor, é Intérprete».

${ }^{5}$ La labor de los párrocos fue desapareciendo con la entrada del siglo XIX, después de producirse varios conflictos. MADARIAGA ORBEA, J. J., «Expresiones culturales y mentales en la Euskal Herria de los siglos XVI al XIX», RIEV, 46-1 (2001), pp. 276-277: «El mecanismo de intermediación socio-lingüística arriba mencionado, consistente en traducir desde el púlpito los acuerdos político-administrativos que afectaban a la comunidad frecuentemente monolingüe, entró en crisis a lo largo del siglo XVIII y se derrumbó a mediados del XIX. Cada vez se daban con más frecuencia incidentes entre los eclesiásticos y las autoridades civiles 
con el poder: recibir mensajes originados en castellano o para escribir documentos públicos; además, su participación en los asuntos públicos se veía disminuida ${ }^{6}$.

Por otro lado, también podemos citar otras disposiciones más favorables al euskera como la de las Juntas Generales de Bizkaia, el 12 de septiembre de 1814: «Trata del método que deberá observarse en lo sucesivo en el nombramiento de dependientes. Acuerda la Junta que siempre que la Diputación tuviese que nombrar algunos dependientes por muerte, u otro cualquier motivo de los actuales, recayga el nuevo nombramiento en Vizcaynos originarios, advirtiendo que la mitad de los tales empleados hayan de poseer el idioma vascongado para conseguir de este modo el mejor servicio del país ${ }^{7}$.

Asimismo es necesario distinguir el plano escrito y el oral en este tema de las relaciones de los ciudadanos con el poder político. En lo que respecta al plano escrito, ciertamente no era habitual redactar textos en euskera, si bien son numerosos los ejemplos contrarios $^{8}$ (desde traducciones completas hasta resúmenes o apuntes para someterlos a explicación oral ${ }^{9}$ ).

En el plano oral, en cambio, el euskera tenía mayores posibilidades de utilización (verdadera necesidad, en ocasiones) como lo demuestran los

por este motivo; los primeros consideraban este trabajo impropio de su dignidad y de la del templo, sobre todo cuando se descendía a labores de pregonero, dando cuenta de bandos sobre caza y pesca, quema de rastrojos, etc., mientras que los segundos se acogían a la tradición para conseguir que se siguiese manteniendo el servicio. Hubo enfrentamientos a causa de las publicaciones en "lengua vulgar" en 1710 en Hondarribia, en 1767 en Santa Marina de Bergara, en 1806 en Segura, etc. En 1832 el Obispo de Pamplona prohibió el mantenimiento de esta costumbre y paulatinamente fueron cesando las lecturas».

${ }^{6}$ El ejemplo arquetípico es el de los alcaldes y procuradores a Juntas en Gipuzkoa y las sanciones a los apoderados vizcaínos desconocedores del castellano en Gernika. A pesar de ello, como señalaremos más adelante, numerosos testimonios nos hablan de un bilingüismo a nivel oral, que sería innecesario si todos los procuradores dominasen el castellano.

7 Juntas Generales del M.N. y M.L. Señorío de Vizcaya celebradas en Santa María de Guernica los días $1 .^{\circ}, 2^{\circ}, 3 .^{\circ}, 4^{\circ}, 5^{\circ}, 6^{\circ}, 7^{\circ}, 8^{\circ}, 9^{\circ}, 10,11,12$ y 13 de Septiembre de 1814, Por Francisco de San Martín, Bilbao, 1814, p. 121.

${ }^{8}$ Ejemplos de documentos jurídico-administraivos redactados en euskera: ordenanzas municipales, cartas entre autoridades administrativas, proclamas y avisos (muchos de ellos desaparecidos). Una recopilación de los conocidos hasta ahora en TREBIÑo, Imanol, Administrazio zibileko testu historikoak, Herri Arduralaritzaren Euskal Erakundea / Instituto Vasco de Administración Pública, Bilbao, 2001.

9 Citemos, como ejemplo, el Convenio de Bergara, que dio fin a la Primera Guerra Carlista; sus archiconocidas cláusulas, ¿por cuántos labios habrán sido pronunciadas en euskera sin que hayan llegado a nuestro días?, ¿cuántas y cuántas explicaciones y traducciones habrá tenido? Una de ellas se puede ver en GALlASTEGI, C., LOBERA, G. eta URRUTIA, A., «Bergarako 1839 ko ituna eta XIX. mendeko udal administrazioko beste testu batzuk euskaraz», Karmel, 4 (1999), pp. 45-52. 
testimonios al respecto. A modo de ejemplo, recogemos lo que escribía Humboldt hacia 1801 sobre las Juntas Generales de Gipuzkoa: «la exposición es siempre en castellano. Sólo se explica lo dicho, cuando el asunto es importante, en vascuence a los que no saben castellano» ${ }^{10}$. Y refiriéndose a Bizkaia: «En las juntas generales mismas domina, sin embargo, una casi ilimitada libertad y un verdadero espíritu de independencia, y la presencia del corregidor no impide que cada cual diga libremente su opinión. En muchos casos también se ausenta él, y a menudo se habla en vascuence, que él no comprende. Hasta hace él mismo leer en ambos idiomas en muchos casos los memoriales en discusiones de interés general» ${ }^{11}$.

Son precisamente las Juntas Generales una institución pública que nos puede dar una medida del papel del euskera en el ámbito público a lo largo del siglo ${ }^{12}$ :

a) a nivel escrito, aparición esporádica de documentos en euskera, fundamentalmente el discurso de apertura de las Juntas por el Corregidor, que es traducido e incorporado a las actas.

b) a nivel oral, utilización por los apoderados en sus intervenciones del idioma elegido y posterior traducción; posibilidad de traducir informes y expedientes al euskera. Además, las actas escritas en castellano se vierten oralmente al euskera antes de ser aprobadas. Todos estos extremos aparecen regulados en los reglamentos de funcionamiento de las Juntas.

c) en ocasiones se toman medidas relacionadas con la lengua vasca: la ya citada de que la mitad de los empleados al menos sea euskaldun, las relacionadas con enseñanza o la creación de una cátedra de vascuence... ${ }^{13}$

Resumiendo, el euskera mantenía una presencia limitada pero real en las instituciones del sistema foral. Más concretamente, desde estas instituciones la supervivencia y, sobre todo, la adopción de medidas favorables a la lengua vasca era posible o la adaptación de la ley española

10 Humboldt, W. F. von, Los vascos (apuntaciones sobre un viaje por el país vasco en primavera del año 1801), Auñamendi, Donostia, 1975, p. 51. A lo largo del siglo XIX también podemos encontrar referencias a explicaciones en euskera, como se lee en las Actas de las Juntas de 1834 (p. 68) cuando se discute el Estatuto Real.

11 Humboldt, W. F. von, ibidem, p. 161.

12 El estudio completo sobre este tema en Urrutia, Andrés (zuz.), Bizkaiko Batzar Nagusiak eta euskara: 1833-1877. Euskarazko testuen bilduma eta azterketa, Bizkaiko Batzar Nagusiak, Bilbao, 2003.

13 Puede leerse un resumen de este tema en Herbosa, A., «Traducciones, declaraciones y jaculatorias. El euskera en las instituciones forales vizcaínas en el siglo XIX», Historia contemporánea, 7 (1992), pp. 297-310. 
igualitaria. ¿Qué ofrecía el liberalismo, el nuevo régimen, en este aspecto? ¿Qué se podía esperar de un proyecto que tiende a la uniformidad?

La experiencia al otro lado de los Pirineos no podía ser esperanzadora. Iniciada la Revolución francesa en 1789, tras una etapa en que el Estado impulsó la traducción de textos jurídico-políticos en euskera con el objetivo de lograr la mayor difusión ${ }^{14}$, la situación cambió radicalmente, convirtiéndose el nuevo régimen en enemigo encarnizado de toda lengua distinta del francés (el euskera, la lengua del «fanatismo»). En España era, por tanto, previsible que la asunción de modelos franceses ${ }^{15}$ trajera a la larga la adopción de medidas contrarias a la lengua vasca (medidas que se fueron produciendo más lentamente que en Francia y a lo largo de todo el siglo en materia de educación, registro civil, notariado, derecho procesal, etc.).

Pero retomemos el hilo, y sin olvidar la situación expuesta como punto de partida, hagamos un recorrido por algunos de los acontecimientos del siglo XIX y la aparición esporádica de textos en euskera o de medidas sobre su estatus que provengan de las filas liberales, sea a modo particular o desde el poder.

\section{EI Trienio Liberal}

\subsection{La instalación del liberalismo en el poder: la Carta Pastoral de Luis de Borbón, de 15 de marzo de 1820}

Entre 1820 y 1823 se produce un nuevo periodo liberal que recupera la Constitución de Cádiz y desarrolla su obra. El liberalismo se instala de nuevo en el poder ante la incapacidad del régimen absoluto; tres años después se extingue, falto de apoyos, pero dejando una importante huella.

14 Pueden verse algunos de esos textos en Rica EsnAOLA, Margarita, «Traduction en basque de termes politiques sous la revolution», Anuario del Seminario de Filología Vasca "Julio de Urquijo», IX (1975), pp. 3-172, y SALABuRU, Pello, «Frantziako iraultza garaiko euskal dokumentu batzuk», Euskera, XXXII-2 (1987), pp. 209-230.

15 En realidad, los Borbones, tanto en Francia como en España, ya habían tomado medidas en favor del francés y castellano, respectivamente, medidas para «extender el idioma general de la Nacion para mayor armonía, y enlace recíproco» (Real Cédula de su Magestad a consulta del Consejo, reduciendo el arancel de los derechos procesales á reales de vellon en toda la Corona de Aragón, y para que en todo el Reyno se actúe y enseñe en lengua Castellana, con otras cosas que expresa, 1768). El estreno de los Borbones en Cataluña (Decreto de Nueva Planta, 1716) contenía disposiciones en favor del castellano en el ámbito judicial. 
La sublevación iniciada en Cabezas de San Juan por Rafael Riego se extiende poco a poco y en marzo el monarca se compromete a jurar la Constitución. Se constituye una Junta Provisional Consultiva, como organismo de transición hasta la reunión de las Cortes y cuya presidencia asumió el cardenal arzobispo de Toledo Luis de Borbón.

Luis de Borbón ${ }^{16}$, tío del rey, contaba con escaso peso político, no había impulsado la rebelión pero su designación se debía al vago prestigio con que contaba entre los liberales; constituía una señal de moderación.

En esos momentos el Cardenal publicaba, con fecha de 15 de marzo de 1820, una pastoral en favor de la Constitución. Como había ocurrido unos años antes Luis de Borbón invitaba al clero y a los fieles a obedecer y acatar el régimen liberal. Este texto fue un apoyo importantísimo para los liberales: defendía la compatibilidad entre el nuevo régimen y la Iglesia, entre el liberalismo y la religión, es más, el disidente era un mal ciudadano español. Acompaña a las palabras del Cardenal, la declaración de Fernando VII de 10 de marzo.

El texto de la pastoral tuvo una gran difusión: según señala Carlos M. Rodríguez, además de su edición primigenia en Madrid, se hicieron reimpresiones a cargo de varios obispos españoles; también existe una edición ese mismo año en México.

Por lo que concierne a nuestro estudio, el texto tuvo su correspondiente edición en euskera ${ }^{17}$. En efecto, durante el mismo 1820 aparecía impreso en Bilbao ${ }^{18}$ el Luis de Borbon, Jaungoicuaren onerichiz...

La traducción fue obra de Vicenta de Mogel, personaje curioso de la historia de la literatura vasca. En efecto, Vicenta pertenece a una familia de literatos vascos y figura como la primera mujer destacada en la literatura vasca, en un momento en el que era extraño que una muchacha estudiase latín y adquiriese una cultura semejante ${ }^{19}$. Publicó en 1804, a los 22 años, el Ipui Onac, libro de fábulas inspiradas en Esopo.

16 Rodríguez López-Brea, Carlos M., Don Luis de Borbón, el Cardenal de los liberales (1777-1823), Junta de Comunidades de Castilla-La Mancha, Toledo, 2002.

17 No era la primera carta pastoral que se traducía al euskera, existen versiones resumidas y textos completos de pastorales en el País vasco peninsular; en el País vasco continental se tradujo al euskera a Sanadón, obispo constitucional.

18 Puede leerse el texto completo en AltziBar, Xabier, Bizkaierazko idazle klasikoak, Diputación Foral de Bizkaia, Bilbao, 1992, pp. 339-351. Dando noticia de este texto: URQUiJo, Julio, «Notas de Bibliografía Vasca. Carta Pastoral en vascuence del Primado de las Españas», Revista Internacional de Estudios Vascos, XXV, 1934, pp. 678-682. No se conservan apenas ejemplares del texto en euskera, por lo que podemos aventurar que no tuvo gran repercusión.

19 Nacida en Azkoitia, donde su padre era médico, sobrina de Juan Antonio (autor de Peru Abarka y un personaje fundamental en las letras vascas, que ya ha aparecido citado 
Sin embargo, no podemos asegurar que Vicenta sea partidaria del liberalismo, pese a la traducción del texto de Luis de Borbón. Mas bien aparece como miembro del reducido círculo vascófilo que durante esos años podemos identificar en la capital vizcaína. Otros participantes de ese círculo son Eluterio de Basozabal (su marido) o José Pablo Ulibarri (a quien corregía sus trabajos) ${ }^{20}$. Además se atribuyen a Vicenta la autoría de distintos versos navideños (algunos de ellos de tendencia conservadora) y labores de traducción para la Diputación, sin que exista en este último caso prueba alguno de ello ${ }^{21}$.

\subsection{Los sermones en defensa de la Constitución}

Para el liberalismo era fundamental sumar apoyos entre la Iglesia ${ }^{22}$, pues en ese momento constituía la principal fuente de información para los temas públicos. Desde los púlpitos se transmitían desde antiguo las disposiciones gubernativas más importantes, según señalábamos al inicio del artículo, antes de la generalización de los pregoneros (que no podían existir en los pueblos pequeños) y boletines oficiales. Por otro

en este artículo) y hermana de Juan José Moguel (autor de varias obras en euskera y dirigente carlista). En las obras de estos dos autores, por cierto, se pueden encontrar pasajes en los que se describen instituciones jurídicas forales (como la libre designación de heredero del derecho foral vizcaíno, en Juan Antonio Moguel, muerto en 1804) o de derecho español (la pragmática sobre promesas de matrimonio dada por Carlos IV en al año 1803; Novísima Recopilación, X, 2, 18 (R.D. de 10 de abril de 1803 inserto en Pragmática de 28, en Juan José Moguel). A falta de literatura propiamente jurídica, resultan especialmente interesantes para el jurista euskaldun este tipo de pasajes. También son de gran interés los datos que aportan sobre el cultivo y el aprecio de la lengua vasca entre sus hablantes pero también de las dificultades que ponía el Estado para publicar en lengua vasca.

20 José Paulo Ulibarri (1775-1847), alavés de nacimiento pero residente en Abando, ejerció varios cargos públicos tanto a nivel local como provincial, siendo apoderado en las Juntas Generales de Gernika. Ulibarri es conocido por su afición al euskera; promovió en 1815 el primer almanaque en euskera: Egutegi eusquerascoa, deseoso de utilizar el euskera con todos (incluso con el rey) y en toda ocasión (intentó sin éxito que del Fuero de Bizkaia se hiciera un traducción del euskera), amén de que se tomaran medidas para su fomento (educación).

21 Altzibar, Xabier, Ibidem, pp. 295-310.

22 En el capítulo de conclusiones de su estudio sobre el Trienio en Gipuzkoa, Felix Llanos se pregunta, después de identificar algunos núcleos urbanos liberales: «¿Podía haber arraigado este liberalismo en las poblaciones rurales? En algunos lugares como Amézqueta o Segura hubo voluntarios entre molineros, boticarios, confiteros, cirujanos o carpinteros. Siempre dependiendo también del entusiasmo constitucional de algún clérigo local. Pero no fue el caso habitual». Llanos Aramburu, Félix, El Trienio Liberal en Guipúzcoa (1820-1823), Universidad de Deusto, Donostia-San Sebastián, 1998, pp. 504-505. 
lado, la actitud de la iglesia fue fundamentalmente antiliberal ${ }^{23}$, si bien se producían en ocasiones apoyos al nuevo régimen, en ocasiones forzados (haciéndoles incluso responsables de la actitud del pueblo) y en otras sinceros.

El poder obligó al clero a difundir la Constitución desde el púlpito y sus predicaciones ${ }^{24}$, como consta en la R.O de 24 de abril de 1820 , que más adelante recogemos. Pues bien, en este caso nos encontramos con que al menos se conserva un sermón de este tipo en euskera en los Archivos de la Casa Zabala.

Se trata de un texto en favor de la Constitución atribuido a Martín de Galarraga, presbítero, natural de Belaunza, y que fue capellán y administrador del Conde de Villafuertes ${ }^{25}$. Este sacerdote sufrió al término del Trienio persecución por sus simpatías liberales.

\subsection{La extensión de la cultura política: los catecismos políticos}

\section{a) LA EXTENSIÓN Y OBLIGATORIEDAD DE LOS CATECISMOS POLÍTICOS}

Durante el Trienio, a diferencia de la primera etapa liberal, se realizaron serios esfuerzos por divulgar el nuevo orden político: sociedades patrióticas, prensa, folletos... en definitiva se pretende acrecentar la cultura política del pueblo ${ }^{26}$.

A esta labor debía contribuir poderosamente el sistema educativo. En efecto, la propia Constitución de 1812, nuevamente en vigor, establecía la inclusión de la enseñanza cívica ${ }^{27}$, recogida a su vez en el artículo 12 del Reglamento General de Instrucción Pública.

${ }^{23}$ La Iglesia se veía perjudicada con la implantación del sistema liberal: reducción del diezmo, desamortización, anulación del fuero eclesiástico... Véase, sobre la actitud del clero, Rubio Pobes, Coro, Revolución y tradición. El País Vasco ante la Revolución liberal y la construcción del Estado español, 1808-1868, Siglo Veintiuno de España Editores, Madrid, 1996.

${ }^{24}$ Véase, CARreÑo Rivero, Myriam, Las ideas de la oratoria sagrada como medio de educación cívica en los inicios del liberalismo español (1820-1823), Universidad Complutense, Madrid, 1990.

${ }^{25}$ Sobre la trayectoria de este personaje CAJAL VAlero, Arturo, «Paz y Fueros». El Conde de Villafuertes. Guipúzcoa entre la «Constitución de Cádiz» y el Convenio de Vergara (1813-1839), Biblioteca Nueva, Madrid, 2002.

${ }_{26}$ Con expresiones en Gipuzkoa como las sociedades patrióticas en San Sebastián y Tolosa, o prensa como El Liberal Guipuzcoano.

27 Señala su artículo 366: «En todos los pueblos de la Monarquía se establecerán escuelas de primeras letras, en las que se enseñará a los niños a leer, escribir y contar, y el catecismo de la religión católica, que comprenderá también una breve exposición de las obligaciones civiles». 
Para llevar a la práctica este mandato llegaron desde Madrid órdenes a las autoridades provinciales. Así, la Diputación Provincial de Gipuzkoa dirigió una circular a los ayuntamientos el 5 de mayo de 1820 , recogiendo la R.O. de 24 de abril de 1820 sobre la divulgación de los principios constitucionales (donde se hablaba además la explicación de la Constitución en las escuelas, de otra más general, para los ciudadanos, explicaciones que, al menos, se produjeron en Tolosa y Bergara) ${ }^{28}$.

La Diputación además de dar esas instrucciones, se ocupó, en septiembre de 1820, de la forma de divulgar la Constitución en Gipuzkoa. Para ello nombró una Comisión de Diputados para que examinasen las cartillas constitucionales ${ }^{29}$ del momento, eligieran una y la adoptasen para la provincia, después de añadirle las aclaraciones oportunas. Además la cartilla adoptaría un formato bilingüe: castellano y euskera ${ }^{30}$.

A continuación hablaremos de los dos textos explicativos de la Constitución en euskera que se conocen, amén de su autoría.

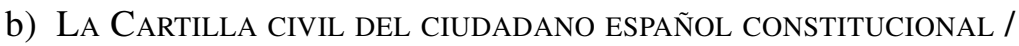 ESPAÑIACO URITAR CONSTITUCIONALEN CARTILLA CIVILLA}

Poco después de las gestiones de la Diputación, un particular, «el ciudadano Manzanares», remitía a la Diputación una exposición al respecto junto con varios ejemplares de una cartilla civil bilingüe publicada

28 En el punto n. $^{\circ} 2$ de esta R.O. se establecía: «En todas las escuelas de primeras letras y humanidades del reino se explicará por los maestros la Constitución de un modo claro y perceptible a la comprensión de los niños, a quienes se familiarizará con la lectura, ejercitándolos en la del mismo Código Fundamental.» En el punto n. ${ }^{\circ} 1$ se trataba de la explicación de la Constitución por Curas Párrocos en sus iglesias («Los Prelados diocesanos cuidarán de que todos los Curas Párrocos de la Monarquía, o los que hicieren sus veces, expliquen a sus feligreses en los domingos y dias festivos la Constitucion politica de la Nacion, como parte de sus obligaciones; manifestándoles al mismo tiempo las ventajas que acarrea á todas las clases del Estado, y rebatiendo las acusaciones calumniosas con que la ignorancia y la malignidad hayan intentado desacreditarla»), así hasta 8 puntos.

Similar es la circular del Jefe Político Interino de Bizkaia (Archivo Foral de Bizkaia, Sección Administrativa, J-00686/215).

${ }_{29}$ Sobre los catecismos políticos CAPITÁn Díaz, Alfonso, Los catecismos políticos en España (1808-1822). Un intento de educación política del pueblo, Caja General de Ahorros y Monte de Piedad, Granada, 1978; RuIz, N.M., «El género catequístico-político», Trienio, n. ${ }^{\circ}$ 26, 1995, pp. 15-65; Catecismos políticos españoles. Arreglados a las Constituciones del Siglo XIX, Consejería de Cultura de la Comunidad de Madrid, Madrid, 1989.

30 «Y que poniéndose en castellano, y al otro lado su versión en bascuence, se presente a la Diputación a fin de que después de examinada se dé a la prensa con la mira de repartir sus ejemplares en todos los pueblos en número bastante para que sirvan a la juventud en las escuelas de primeras letras.» 
a sus expensas ${ }^{31}$. Se trata de un pequeño libro, publicado en Tolosa, que recoge las explicaciones más básicas de la doctrina constitucional. La Diputación, en una circular de 14 de noviembre, explicaba esta circunstancia e invitaba a los ayuntamientos a su uso.

Tenemos datos del grado de utilización de este texto bilingüe: dos pueblos, Plasencia y Errezil, al menos la usaron, según se desprende de los testimonios enviados por los pueblos sobre el cumplimiento de la R.O. de 24 de abril de 1820. Sin embargo, el texto más manejado en los pueblos de Gipuzkoa era el Catecismo Político, de D.J.C. ${ }^{32}$, obra de la que a continuación nos ocuparemos.

\section{c) El Catecismo Político/Jaquin-bide Iritarautia}

Depositado en la biblioteca de los Capuchinos de Hondarribia reposó hasta $1987^{33}$ un manuscrito que contenía una explicación en euskera de la Constitución de 1812 y que databa de 1820 .

Anónimo (aparecían las iniciales del autor castellano y las de su traductor al euskera, como era habitual en este tipo de obras), el texto se abría con una dedicatoria a Miguel de Zumalacarregui, el hermano liberal del célebre general carlista, que en su andadura llegó a ocupar el cargo de ministro.

Este manuscrito fue publicado en forma de facsímil en $1991^{34}$.

\section{d) LA AUTORÍA DE LOS DOS CATECISMOS POLÍTICOS EN EUSKERA}

A continuación queremos plantear el problema de la autoría de estas dos obras, o más bien, de la responsabilidad de su traducción al euskera.

El primer libro, el publicado en Tolosa, apareció sin expresión de su autoría («por un ciudadano amante de la Constitucion y demas de la

31 Cartilla civil del ciudadano español constitucional... Tolosa, Juan Manuel de la Lama, 1820, ocupa 65 páginas.

32 Esta obra, considerada la primera obra que glosó la Constitución de Cádiz, contó con innumerables ediciones y aunque el autor había muerto en 1829 fue adaptada su obra a la Constitución de 1837 dando lugar a nuevas ediciones de la obra. En 1820 apareció en Donostia impresa en la imprenta de Ignacio Ramón Baroja.

33 San Martín, J., «Cadizko Konstituzioa euskaraz», Euskera, 1987-2, n. 32, 1987, pp. 393-397.

34 Jaquin-bide Iritarautia Españiaco Neurquidaren edo Constitucio berriaren erara adrezatua Erritarren arguidoraraco, gazteen icasbideraco eta Escola-maisuen usoraco. Erderatic Eusquerara itzulidu Apez Vicario D.D.J.J.A. Gipuztarrac. 1820n urtean, Ararteko, Eusko Legebiltzarra / Parlamento Vasco, Vitoria-Gasteiz, 1991. 
ilustracion del pueblo / Constitucio au, ta españiar gucien arguia, edo ulustracioa, ta batez ere gende mearena chit maite dituan batec moldatuac» se lee en su portada interior), si bien gracias a las investigaciones de Jesús de Benito conocemos las vicisitudes del ofrecimiento de la obrita por su autor a la Diputación, después de que ésta se interesara por la preparación de una obra de este tipo, y de cómo la institución guipuzcoana recomendó y ofreció ejemplares de la obra de Manzanares a los pueblos.

Sin embargo, ¿es el propio Manzanares el autor de la versión en euskera del texto? Leemos en La Voz de Guipúzcoa de 17 de diciembre de 1897: «Urreta fue autor de un catecismo liberal, única obra en su género que se ha escrito en el vigoroso idioma euskaro» ${ }^{35}$. Este dato nos abre la posibilidad de que Urreta escribiera el texto en euskera de la Cartilla civil. Este Urreta no es otro que Juan Ignacio Urretabizkaia, párroco de Amezketa en esa época y conocido además por aparecer en los relatos de Pernando Amezketarra, personaje popular en el País Vasco, protagonista de mil anécdotas y cuentos.

En cuanto al texto en euskera del Catecismo político, las iniciales D.D.J.F.A. que nos señalan la autoría de la traducción (pues se basa en un texto español bien conocido) fueron desveladas por Angel Ibisate ${ }^{36}$,

35 Aparece esta frase en un artículo titulado Cosas de la tierra: D. Juan de Urreta, firmado por Calei-Cale (seudónimo de Eugenio Gabilondo) donde se recogen algunas notas de su vida; podemos leer sobre su labor: «Tal influjo alcanzó a tener el gran Urreta, y llegó a adquirir tal dominio sobre las gentes, liberalizando a todo el pueblo e inculcando en el ánimo de sus convecinos ideas de civilización y progreso, que para explicar en Goyerri la influencia de las nuevas ideas y la transformación radical sufrida por el pueblo amezquetano, se generalizó la frase, que se hizo célebre, de sintetizar el proceso diciendo: "Amezquetan Jaungoiko berriya eguin dute" (en Amézqueta han creado un nuevo Dios) aludiendo al espíritu que reinaba en el vecindario».

Para más datos sobre Juan Ignacio Urretabizkaia veáse ZaBALA, Antonio, Karlisten lee-

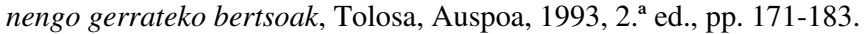

36 Permítasenos una pequeña anécdota. En el verano de 1994 me ocupé de indagar sobre la autoría de esta traducción; las iniciales del personaje anónimo aparecían en la portada del manuscrito: Dr. D.D.J.F.A.; sin embargo, cuando tras varias pesquisas contacté con el Archivo Diocesano de Pamplona, la lacónica respuesta fue: «No se moleste, hace pocas fechas otra persona vino en busca de ese dato». Quien se había adelantado en la resolución del enigma era D. Angel Ibisate Lozares, bibliotecario del Seminario Diocesano de Vitoria-Gasteiz y a posteriori amigo. Me queda el consuelo de informarle de la autoría del texto original, Don José Caro y Sureda. Véanse sus trabajos al respecto IBISATE, A., «El original castellano del Jaquin-bide Iritarautia del Dr. D. J. F. A.». Scriptorum Victoriense 39, 1992, pp. 222-227; IBISATE, A., «El Doctor Don José Feliz Amundarain (Cegama 1755Mutiloa 1825), autor del Jaquin-bide Iritarautia (1820)». Boletín de la R.S.B.A.P. L, 1994-1, pp. 159-169.; y, además, SAN MARTín, J., «Dr. D. Jose Felix Amundarain Mujika eta Cadiz-ko Konstituzio euskaratuaz zenbait ohar». Egan L, 1998, pp. 242-244. 
dando a la luz el nombre de un nuevo escritor vasco: José Felix Amundarain (1755-1825).

Afortunadamente sobre Amundarain existe un estudio ${ }^{37}$ donde se recogen los pormenores de su azarosa vida y algunos de los sermones en euskera ${ }^{38}$ que el autor recopiló, sin éxito, para su publicación.

Los autores de este estudio se preguntan por la sinceridad del liberalismo de Amundarain, a la vista del contenido de los sermones; en ellos aparecen críticas a los últimos sucesos políticos y a la política llevada por el poder político con respecto a la Iglesia católica. Pero tal vez, reconocen, esta etapa sea un intento para evitarse problemas en los últimos años de su vida ${ }^{39}$ (téngase en cuenta que Amundarain tradujo el catecismo político liberal a los 65 años y que murió pocos años después).

\subsection{La defensa del régimen liberal: la Milicia Nacional}

En el nuevo sistema militar se incluía la Milicia Nacional, la cual a nivel local era un órgano voluntario de defensa del orden constitucional $^{40}$.

Un texto fundamental es el Reglamento provisional para la Milicia nacional, publicado en septiembre de 1820 . Pues bien, este texto normativo tuvo su correspondiente traducción al euskera, si bien hasta nuestros días no ha sido divulgado ${ }^{41}$. ¿A quién corresponde esta traducción? El texto del reglamento está acompañado de una carta en castellano y una dedicatoria en euskera al Conde de Villafuertes. He aquí el texto de la carta fechada en Segura, el 16 de noviembre de 1820, y dirigida al Jefe Político de Gipuzkoa: «La oficialidad de la Milicia Nacional local de Segura deseosa que sus indibiduos se enterasen de

37 IDIAKEZ, A. et al., Jose Felix Amundarain Muxika (Zegama, 1755-Mutiloa, 1825), Goierriko Euskal idazle ezezaguna. Goierriko Euskal Eskola Kultur Elkartea, Lazkao, 1998.

${ }^{38}$ Los 48 sermones fueron localizados por Jerardo Elortza en la biblioteca del Convento de los Benedictinos de Lazkao.

39 IDIAKEZ, A. et al., ibidem, pp. 76-80.

40 Sobre la milicia nacional PéREZ GARZón, Juan, Milicia nacional y revolución burguesa. El prototipo madrileño (1808-1874), Consejo Superior de Investigaciones Científicas, Madrid, 1978.

41 Presentamos este texto en el XV Congreso Internacional de la Real Academia de la Lengua Vasca-Euskaltzaindia; Urrutia A. y Gallastegi, C., Euskarazko lexikogintza juridiko-administratiboa. Larramendiren eragina, Euskaltzaindiaren Nazioarteko XV. Biltzarra, Bilbao, 2001, pendiente de publicación. 
sus deveres, penso traducir al bascuence el reglamento remitido por las Cortes para su organizacion, al efecto se valio del celo patriotico, y talentos conocidos de D. Jose Felix de Amundarain, vicario de la Parroquia de Mutiloa, quien a las treinta horas de su embio, nos remitio la copia que incluimos a $\mathrm{S}$. Creemos ser muy util a los que componen la de esta y no menos del resto de la Provincia por lo que nos tomamos la libertad de remitirsela a su S. para que de ella haga el uso que le dicte su prudencia».

Nuevamente debemos referirnos pues a José Félix de Amundarain, el vicario de ideas liberales (decimos esto ya que parece claro que Amundarain hizo por el régimen del Trienio más de lo que se le podía exigir; además lo hizo teniendo en cuenta la lengua de sus paisanos).

Una vez más el trabajo desarrollado por Amundarain quedó sin ver sus frutos. La debilidad del nuevo régimen, la falta de medios y costumbre... hicieron que este otro texto del vicario de Mutiloa quedara de nuevo sepultado entre papeles.

Y si estamos hablando de la Milicia Nacional, queremos referirnos a continuación a los voluntarios realistas, fuerzas que debían defender el absolutismo a la manera que lo había hecho la Milicia Nacional con el liberalismo, una vez que Fernando VII recuperara el poder. Curiosamente el Reglamento que preparó en 1825 la provincia de Gipuzkoa, acomodando la legislación española al sistema foral, preveía en la instrucción de los tercios, cada vez que se reunieran para la instrucción, la lectura de un capítulo de los Fueros de Gipuzkoa, y que, a continuación, se hiciera la explicación oral de su contenido en euskera ${ }^{42}$.

\section{Primera Guerra Carlista: prensa y propaganda}

\subsection{Las iniciativas liberales}

En 1833 se inicia la primera guerra carlista. Dos bandos se enfrentan con violencia en Euskal Herria. Durante esta guerra se inicia la publicación de manifiestos y proclamas por ambos bandos. Por primera vez se dirigen al pueblo hojas de contenido político, si bien se refieren generalmente a ofrecimientos a deponer las armas.

En efecto, iniciadas las hostilidades Pedro Sarsfield al mando del ejército cristino entraba en Bilbao a finales de noviembre y el día 28 la

42 Se puede ver este texto en la Colección de folletos digitalizados de la biblioteca Koldo Mitxelena Kulturunea (www.gipuzkoa.net/kultura/km). 
Diputación dirigía una proclama bilingüe con el título Paisanos armados de Vizcaya, en euskera Vizcaico erritar armadunac ${ }^{43}$. A lo largo de la guerra habrá más hojitas bilingües de este tipo ${ }^{44}$, tanto liberales (incluidas las maniobras de Aviraneta) como carlistas.

En cuanto a la prensa, los liberales se plantearon la necesidad de divulgar sus ideas, extremo que alcanzó al euskera y que produjo que los primeros textos en euskera en la prensa aparecieran en 1834 en un periódico liberal, concretamente en El Correo del Norte. Periódico político, literario y comercial ${ }^{45}$.

En febrero de 1834 el Ministerio de guerra remitía al ministro de fomento una carta pidiendo la publicación inmediata de una revista en Donostia, «cuyo principal objeto sea el desvanecer las falsas noticias que propalen los rebeldes, inspirar la justa confianza que se merece el maternal Gobierno de S.M. y la seguridad de las ventajas que todos los españoles deben con el Reynado de su augusta Hija». El secretario del Ministerio de fomento contestó afirmativamente, apelando a la urgencia del proyecto, y a su vez el Ministerio de guerra dirige una comunicación a los responsables de la Diputación de Gipuzkoa con dicho mensaje. Si bien no se conoce el resultado inmediato de estas gestiones del mes de febrero, pocas semanas después aparece El Correo de Norte $^{46}$, primer periódico que incluyó entre sus páginas el euskera ${ }^{47}$. Así, en el número 18 de este periódico podemos leer la proclama Erritar maiteac.

Probablemente la necesidad de divulgar sus ideas de forma escrita era mucho menor en el bando carlista. Se pueden citar varias razones

43 Se puede leer este texto bilingüe en Altzibar, Xabier, Ibidem, pp. 314-315. Contiene en sus breves líneas referencias constantes a la cuestión de los fueros.

${ }_{44}$ Otros dos textos los publicábamos en Urrutia, A. y Lobera, G. (ed.), Euskara, Zuzenbidearen hizkera, Universidad de Deusto, Bilbao, 1995.

45 Las noticias que vienen a continuación tomadas de Fernández Sebastián, J., Prensa e ideas políticas en la crisis del Antiguo Régimen (País Vasco, 1750-1840), Madrid: Siglo Veintiuno de España Editores, 1991, pp. 451-454, y DíAZ Nocı, Javier, Euskal prentsaren sorrera eta garapena (1834-1939), Eusko Ikaskuntza, Donostia, 1995, pp. 30-32.

46 Véase la ficha de este periódico en DíAz Noci, Javier, Euskarazko aldizkari, egutegi eta almanaken erroldea (1834-1959), Eusko Ikaskuntza, Donostia, 1994, p. 23.

${ }^{47}$ En 1848 se publicaban en el País Vasco continental Ariel. Uscal-Herrico Gaseta, primera publicación íntegramente en euskera y el primer almanaque Euscaldun laboararien adiskidea; DíAz NocI, Javier, Euskal prentsaren sorrera eta garapena (1834-1939), Eusko Ikaskuntza, Donostia, 1995, pp. 32-35. Anteriormente, en 1843, se habían publicado textos en euskera con fines políticos en el periódico Le Patriote Français de Montevideo, en el marco de la Guerra Grande uruguaya; Menats, Claude, «Articles en basque parus en 1843, dans Le Patriote Français de Montevideo», Lapurdum, VII, 2002, pp. 247-257. 
para ello: dispersión del territorio controlado, menores medios, pobreza ideológica, desprecio por la prensa, analfabetismo de sus bases... y sobre todo el apoyo del clero y otros elementos que hacían innecesaria en esos momentos la propaganda carlista entre el campesinado, ya ganado para la causa de don Carlos.

\section{La construcción del Estado Liberal y la respuesta de las instituciones forales. Contrapropuesta carlista}

Una de las novedades dentro de la etapa intermedia entre la primera guerra carlista y la supresión del régimen foral fue el desarrollo de un sistema educativo fuertemente centralizado. La educación serviría además para la propagación del castellano, postergando el uso de las otras lenguas ${ }^{48}$. Nos referimos evidentemente a la Ley Moyano, dada en 1857, que rompía definitivamente el sistema de educación tradicional.

¿Cómo fue recibida dicha ley en el seno de las instituciones públicas vascas? Citemos solamente la postura adoptada por la Conferencia de las Tres Provincias. En la Conferencia celebrada en Vitoria-Gasteiz, el 6 de noviembre de 1857, los representantes de las tres provincias examinaron la ley de instrucción largo y tendido y decidieron elevar a la Reina un informe muy crítico por su ruptura con el sistema foral. Se oponían, en definitiva, los representantes vascos a su aplicación en el País Vasco.

Respecto a la lengua vasca señalan: «los profesores de la enseñanza primaria deben necesariamente en este país poseer el idioma vascongado» y «suprimida del círculo de la administración foral la preciosa atribución de nombrar los maestros, las escuelas se verán ocupadas por profesores extraños a la lengua y las costumbres especiales de este país» ${ }^{49}$. Son éstas algunas de las manifestaciones del sentimiento que producía la legislación uniformizadora en el País Vasco.

48 Para el tema educativo, véase, como resumen y fuente bibliográfica, LÓPEZ ATXURRA, Rafael, «Historia de las instituciones educativas en Euskal Herria. La enseñanza primaria en el Antiguo Régimen. Pauta para la investigación», en MiEZA, Rafael M. ${ }^{a}$ y GRACIA CÁRCAMo, Juan (ed.), Haciendo historia. Homenaje a M. ${ }^{a}$ Jesús Larrea, Universidad del País Vasco, Bilbao, 2000.

49 Agirreazkuenaga Zigorraga, Joseba (ed.), La articulación político-institucional de Vasconia: Actas de las Conferencias firmadas por los representantes de Alava, Bizkaia, Gipuzkoa y eventualmente de Navarra (1775-1936), Diputación Foral de Bizkaia, Bilbao, 1995, p. 509. 
Durante la Segunda Guerra Carlista las autoridades carlistas tuvieron un gran interés por el euskera. No nos referimos a la producción de documentos, textos dirigidos al pueblo (que siguió en una dinámica parecida: manifiestos y proclamas de uno y otro bando), sino a disposiciones relativas a su estatus.

Tanto en Bizkaia como en Gipuzkoa las autoridades provinciales demostraron un verdadero interés en que el euskera tuviera su papel en la enseñanza. Restaurado el sistema foral de enseñanza (Real Orden de 3 de febrero de 1874), en Gipuzkoa se constituyó una Comisión de Instrucción Pública ${ }^{50}$ y cuyo fruto más importante fue el Reglamento de enseñanza de 31 de diciembre de 1875. Los ambiciosos planes culminaban con la redacción de materiales educativos en euskera. Desde un año antes las Circulares pedían que en la enseñanza se incluyera el euskera.

En Bizkaia, de la misma forma, en 1875 se produjeron movimientos para fomentar el cultivo del euskera dentro del sistema educativo.

\section{La literatura antiliberal de fin de siglo}

Para cerrar este repaso, vamos a referirnos a la literatura política de fin de siglo. En realidad debemos constatar la inexistencia de una literatura liberal en euskera. Dejando a un lado los breves textos en prensa $^{51}$, no existe obra que podamos citar ahora, a diferencia del País Vasco continental, donde nos encontramos con una división de la vida política y social en dos bandos (xuriak / gorriak) con múltiples reflejos en las letras vascas ${ }^{52}$.

Ciertamente la literatura vasca, después del eclipse de mediados de siglo, sufrió en el País vasco peninsular un renacimiento a raíz de la pérdida de los fueros, con numerosos autores y obras. Pero no abarca ese florecimiento la edición de obras de tipo contenido político. Ahora bien, sí hubo ocasión de publicar algunos títulos antiliberales, enmarcados en la política católico-integrista de fines de siglo.

50 Entre sus miembros el sacerdote Jauregi, el cual pidió ayuda para la labor de la Comisión a Ignacio Arana, a quien más adelante haremos referencia.

51 Se puede citar (dando al término «liberal» el sentido amplio que se le atribuye en el País Vasco en esa época) los textos en euskera que aparecieron en periódicos como El Eco de San Sebastián o La Unión Vascongada, ambos publicados en Donostia a finales de siglo.

${ }^{52}$ Hablamos, además de las tentativas de mediado de siglo de Chaho, de revistas como Le Réveil Basque, los textos publicados en otros periódicos y revistas, almanaques, además de las numerosas hojitas de propaganda electoral. Sin embargo, las publicaciones xuriak son más numerosas según nuestros datos. 
El ejemplo paradigmático de este género es la obra El liberalismo es pecado de Félix Sardá y Salvany ${ }^{53}$. Alrededor de este título encontramos varias obras en euskera que enumeramos por orden cronológico:

a) Se inicia la serie con el Liberalen doctrina pecatu da, publicado en Barcelona en 1867, traducción de la citada obra de Sardá.

b) En Bayona se publica, en 1888, el Bai, pecatu da liberalqueriya, en la imprenta de L. Lasserre ${ }^{54}$. Esta obrita en dialecto guipuzcoano presenta a modo de catecismo (preguntas y respuestas) un resumen de la doctrina antiliberal, condenando explícitamente la lectura de algunos periódicos vascos (El Noticiero de Bilbao y La Voz de Guipúzcoa de Donostia).

c) Nuevamente se publica en Barcelona, en 1891, una versión de la obra de Sardá, El liberalismo es pecado. Se trata de la monumental edición políglota, ocho idiomas, que incluyó, además del original, las traducciones a varios idiomas (catalán, francés, portugués, latín, italiano, alemán) y que incluyó una nueva y diferente traducción al euskera ${ }^{55}$.

Ciertamente no hemos señalado nada sobre los responsables de la edición en euskera de estas obras. En realidad hay distintas opiniones al respecto y un verdadero baile de atribuciones de autoría ${ }^{56}$ : D.J.M. Echeverria, Gregorio Arrue Rezola, Juan Ignacio Arana... Sin embargo la consulta del resumen de los diarios del padre Arana que publicó Patxi Altuna ${ }^{57}$ nos

53 Moliner Prada, Antonio, Félix Sardá i Salvany y el integrismo en la Restauración, Universidad Autónoma de Barcelona, 2000.

${ }^{54}$ Se recoge el texto completo en LAKARRA, Joseba A., «Bai, pecatu da liberalqueriya», Anuario del Seminario de Filología Vasca «Julio de Urquijo», t. 23, n. 2 (1989), p. 663-676. Tambien se puede ver el texto en Colección de folletos digitalizados de la biblioteca Koldo Mitxelena Kulturunea (www.gipuzkoa.net/kultura/km).

55 Sardá y Salvany, Félix, El liberalismo es pecado, Barcelona, Establecimiento Tipográfico de la Hormiga de Oro. 1891. Edición políglota monumental (tamaño gran folio, $43 \times 32 \mathrm{~cm}$ ), con textos en castellano, euskera, catalán, portugués, latín, francés, italiano y alemán.

56 Aparecen opiniones contrapuestas y confusiones varias en el artículo Apaiz zar bat (revista Egan, n. ${ }^{\circ} 1-2,1960$, pp. 94-95), en Villasante (Historia de la literatura vasca), en Lakarra (artículo antes citado), en Urquizu (Historia de la literatura vasca), en Jon Bilbao (Eusko Bibliographia), en Onaindia (Euskal Literatura)...

57 Altuna, Patxi (S.J.), Aita Aranaren egunaria, Euskaltzaindia, Bilbao, 2000. Referencias a la traducción publicada en 1891 en las páginas 197, 205, 237 y 294 del resumen de los diarios realizada por Altuna. Curiosamente podemos señalar que Arana, prolífico traductor, se embarcó en la también obra políglota El Concilio III de Toledo, publicada en Madrid en 1891 (incluye textos en castellano, latín, árabe, catalán, gallego, portugués y euskera). 
revela a las claras que la traducción en que intervino el jesuita es la publicada en 1891.

Además debemos señalar que algunos de las autores antes citados mencionan una obra en dialecto vizcaíno del mismo tema, publicada en 1889 , pero que desconocemos.

Y finalmente cerramos este resumen con otro título: la obra de Blas Pradere Arruti, Satanasen bandera edo liberalqueriya osoro da madaricagarriya, publicada en Tolosa, en 1896. 